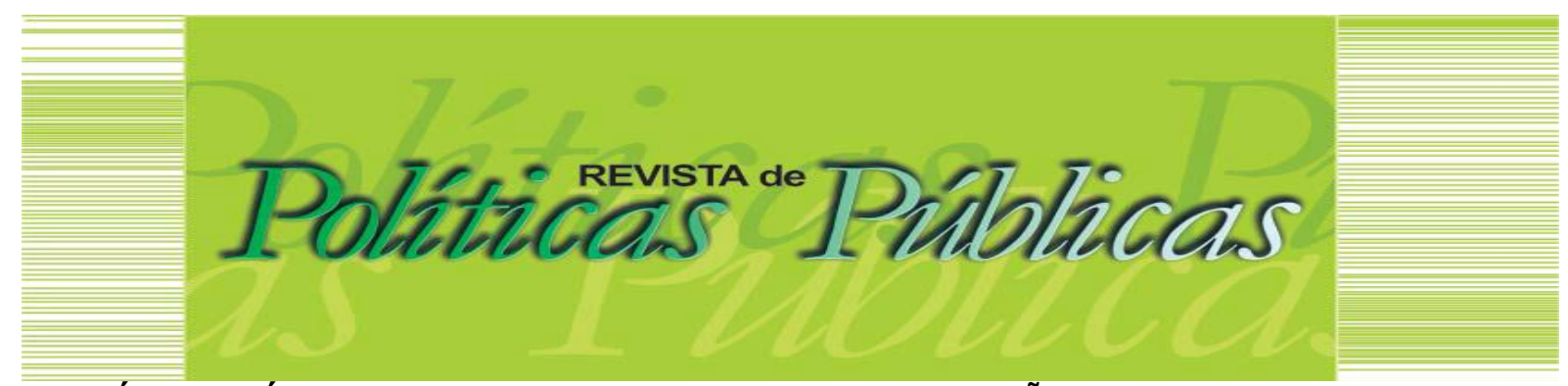

\title{
POLÍTICAS PÚBLICAS EDUCACIONAIS E A DEMOCRATIZAÇÃO DO SABER: Licenciatura em Estudos Africanos e Afro-Brasileiros da UFMA
}

\author{
Marcelo Pagliosa Carvalho ${ }^{1}$ \\ Tanielle Cristina dos Anjos Abreu²
}

\section{Resumo}

Este artigo tem como objetivo analisar as políticas públicas educacionais desenvolvidas pelo governo federal brasileiro para a inclusão das Histórias e Culturas Africanas e Afro-Brasileiras, no período 2003-2019. A Licenciatura Interdisciplinar em Estudos Africanos e Afro-Brasileiros, inaugurada pela Universidade Federal do Maranhão (UFMA), em 2015, é perscrutada enquanto uma possibilidade de ação afirmativa que colabora para a implementação da Lei $n^{0} 10.639 / 2003$ e para a democratização do saber. A legislação federal que afirmou a obrigatoriedade de os currículos inserirem essas Histórias e Culturas e os documentos da Licenciatura são as fontes de informações principais.

Palavras-chave: Políticas Públicas Educacionais. Histórias e Culturas Africanas e Afro-Brasileiras. Estudos Africanos. Educação e Relações Étnico-Raciais.

\section{EDUCACIONAL PUBLIC POLICIES AND THE DEMOCRATIZATION OF KNOWLEDGE: Degree in African Studies and Afro-Brazilian of UFMA}

\section{Abstract}

This article aims to analyze the educational public policies developed by the Brazilian federal government for the inclusion of African and Afro - Brazilian Histories and Cultures in the period 2003-2019. The Interdisciplinary Degree in African and AfroBrazilian Studies, inaugurated by the Federal University of Maranhão (UFMA) in 2015, is examined as a possibility of affirmative action that contributes to the democratization of knowledge. Federal legislation that mandated curricula to enter such Stories and Cultures, such as Law No. 10,639 / 2003 and its correlates, and the Licensure documents are the primary sources of information.

Keywords: Educational Public Policies. African and Afro-Brazilians Stories and Cultures. African Studies. Education and Ethnic-Racial Relations.

${ }^{1}$ Graduado em História. Doutor em Educação pela Universidade de São Paulo (USP). Professor da Licenciatura em Estudos Africanos e Afro-Brasileiros (UFMA). E-mail: marcelo.pagliosa@yahoo.com.br

${ }^{2}$ Administradora. Mestranda no Programa de Pós-Graduação em Políticas Públicas da Universidade Federal do Maranhão.

E-mail: taninhacarioca_91@hotmail.com 


\section{INTRODUÇÃO}

As politicas públicas educacionais voltadas à população negra e à inclusão das Histórias e Culturas Africanas e Afro-Brasileiras nos currículos escolares brasileiros, sobretudo a partir da aprovação da Lei no 10.639/2003 e das legislações dela decorrentes, serão estudadas em dois distintos períodos: a) governos de Luiz Inácio Lula da Silva (2003-2010) e de Dilma Rousseff (2011-2016), que procuraram desenvolver ações afirmativas com o objetivo de mudar o cenário de exclusão educacional dessa população e de ocultamento dessas Histórias e Culturas nos currículos brasileiros, quer na educação básica, quer no ensino superior; b) governos de Michel Temer (2016-2018) e início da gestão de Jair Bolsonaro (2019-em andamento), marcados pelo descaso ou desmonte de muitas das políticas públicas construídas nas gestões anteriores.

Implantada em 2015, a Licenciatura Interdisciplinar em Estudos Africanos e AfroBrasileiros da Universidade Federal do Maranhão (UFMA), curso inédito no Brasil, tenciona contribuir para a formação de profissionais da educação e de formuladores, gestores e avaliadores ligados à administração pública que possam colaborar na construção e desenvolvimento de políticas públicas educacionais para a população negra.

As intencionalidades ou proposições curriculares que alicerçam a proposta pedagógica do curso serão objetos de nossas reflexões. A Licenciatura examinada neste artigo se mostra como uma iniciativa valiosa para que os(as) brasileiros(as) possam ter acesso a essas Histórias e Culturas, sem estereótipos ou romantizações. Histórias que são, inclusive, estruturantes e estruturais da história nacional.

\section{AS POLÍTICAS EDUCACIONAIS E A INSERÇÃO DAS HISTÓRIAS E CULTURAS AFRICANAS E AFRO-BRASILEIRAS}

A desumanidade e a indignidade humana não perdem tempo a escolher entre as lutas para destruir a aspiração humana de humanidade e de dignidade. 0 mesmo deve acontecer com todos os que lutam para que tal não aconteça.

(SANTOS, 2013)

A Lei $n^{0}$ 10.639, de 9 de janeiro de 2003, que altera a Lei de Diretrizes e Bases da Educação Nacional (LDB n 9.394/1996) para tornar obrigatória a História e a Cultura Africana e AfroBrasileira nos currículos escolares brasileiros ${ }^{1}$, é um marco no debate sobre a temática étnico-racial no Brasil, impulsionando: 1) a elaboração de legislações associadas; 2) o desenvolvimento de políticas públicas educacionais para a população negra brasileira; 3) a problematização do eurocentrismo nas 
práticas curriculares; 4) o fortalecimento das identidades e de direitos; 5) a confecção de ações educativas de combate ao racismo e às discriminações.

Foram muitas as conquistas relativas às reivindicações históricas do movimento negro durante as gestões de Lula da Silva (2003-2010) e de Dilma Rousseff (2011-2016): a criação da Secretaria Especial de Promoção da Igualdade Racial (Seppir)2; a promulgação da Lei no 10.639/2003; a fundação da Secretaria de Educação Continuada, Alfabetização, Diversidade e Inclusão (SECADI), órgão do Ministério da Educação (MEC) responsável em desenvolver políticas educacionais à população negra; a instituição das Diretrizes Curriculares Nacionais para a Educação das Relações Étnico-Raciais e para o Ensino de História e Cultura Afro-Brasileira e Africana (BRASIL, 2004) e, em decorrência, do Plano Nacional de Implementação das Diretrizes Curriculares Nacionais para a Educação das Relações Étnico-Raciais e para o Ensino de História e Cultura Afro-Brasileira e Africana (BRASIL, 2009); a aprovação do Estatuto da Igualdade Racial (Lei $\left.n^{0} 12.288 / 2010\right) ;$ a implementação de políticas de ações afirmativas na modalidade cotas nas universidades públicas brasileiras; e a aprovação, de maneira unânime (2012), da constitucionalidade das ações afirmativas pelo Supremo Tribunal Federal (CARVALHO, 2018).

O desenvolvimento de legislações e políticas públicas pelo Estado brasileiro, a partir de 2003, objetivando inserir a população negra brasileira a direitos antes alijados, assinalou uma transformação histórica no que se relaciona à adoção de políticas antirracistas, sobretudo na área educacional, colaborando na tentativa de superação das desigualdades étnico-raciais ainda constantes no país. Por meio de políticas de ações afirmativas, o governo federal procurou atuar no combate da desigualdade material ou substantiva, questionando e atacando a lógica da igualdade abstrata, em especial por se tratarem de direitos concretos de sujeitos marginalizados historicamente, vítimas de ações políticas anteriores que os deixaram no limbo.

É importante ressaltar que essa postura estatal divergiu das políticas públicas realizadas no Brasil para a população negra até então. 0 Estado brasileiro não apenas cometeu equívocos ao adotar uma postura passiva frente ao racismo e à discriminação racial que vitimou essa população, ao se eximir de combater a exclusão social e étnico-racial e a violência ocorridas no período escravocrata ou no pós-abolição. As ações políticas se negaram a incluir essa parcela do povo brasileiro, que ficou desacolhida de direitos humanos, tais como à moradia, à educação, à saúde etc. Mais do que isso: 0 Estado brasileiro teve uma postura ainda mais grave, pois foi intervencionista na constituição e na propagação do racismo e da discriminação racial no país e produziu posturas ativas e permissivas que favoreceram a população branca, deixando a população negra em uma condição de exclusão.

Para suprimir esse panorama histórico de privilégios (à população branca) e de exclusão (aos/às negros/as), torna-se necessária a implementação de políticas de ações afirmativas. A 
transformação social e racial só pode ser alcançada com a defesa dos direitos coletivos dos sujeitos historicamente excluídos:

Os direitos coletivos existem para minorar ou eliminar a insegurança e a injustiça de coletivos de indivíduos que são discriminados e vítimas sistemáticas de opressão por serem o que são e não por fazerem o que fazem. [...]. No continente latino-americano, o reconhecimento dos direitos coletivos dos povos indígenas e afrodescendentes tem tido especial visibilidade política e torna-se particularmente polêmico sempre que se traduz em ações afirmativas, em revisões profundas da história nacional, dos sistemas de educação e de saúde, em autonomias administrativas, em direitos coletivos à terra e a o território [...] (SANTOS, 2013, p. 64).

A criação da Seppir e a aprovação da Lei n 10.639/2003 contemplaram parte significativa das reivindicações históricas do movimento negro. Criada com status de ministério, a Seppir configurou-se como um espaço de poder e representação que fez ressoar tais reivindicações na administração pública, seja pelas ações diretamente realizadas, seja como um órgão que pressionava ou influenciava outros ministérios ou áreas estratégicas.

Mesmo com os avanços citados (período 2003-2016), algumas ações acabaram sendo tímidas: a Lei $n^{0} 10.639 / 2003$ e suas correlatas deixaram de ter 0 impacto esperado porque as ações ou políticas públicas que as fortaleceriam não foram contempladas com recursos financeiros e estruturais suficientes para que pudessem chegar de forma mais robusta às escolas e às universidades; a falta de investimentos alocados na SECADI; a pouca contundência em reconhecer e titular as comunidades quilombolas; a falta de iniciativas relacionadas à diminuição da violência policial e dos altos índices de homicídio contra os(as) negros(as).

Em 2016, após Dilma Rousseff, presidenta da república eleita democraticamente, ter sido retirada do poder pelo Congresso Nacional sem bases comprovatórias que validassem o impedimento da administração - o que se configurou, segundo muitos sujeitos individuais ou coletivos, em um golpe de Estado parlamentar, amparado por decisões (no mínimo) polêmicas do Judiciário e pelo apoio de amplos setores da chamada grande imprensa, que visava defender interesses de grupos hegemônicos derrotados em eleições presidenciais anteriores -, as políticas de inclusão social, de gênero e racial sofreram um enorme retrocesso. Setores sociais conservadores ou reacionários aproveitaram a ocasião para criticar e realizar ações que brecassem a construção de políticas de ações afirmativas para a população negra.

O governo de Michel Temer (2016-2018) não desenvolveu iniciativas inclusivas para a área, como o estímulo de leis e de políticas públicas, ao contrário do que ocorrera nas gestões de seus dois antecessores, e procurou diminuir a amplitude de algumas políticas e ações que estavam em desenvolvimento. O Ministério de Mulheres, Igualdade Racial e Direitos Humanos foi rebatizado para Ministério dos Direitos Humanos, em uma nítida tentativa de desvalorizar a importância de políticas 
identitárias no Brasil. A desembargadora aposentada Luislinda Valois foi nomeada ministra dessa pasta. Sua gestão foi marcada pela inércia e pelas polêmicas em que se meteu³. Mesmo após a sua saída do governo, a pasta continuou a ser criticada por não desenvolver ações com a relevância que a área necessitava. O processo de desmonte da SECADI iniciou-se ainda com Temer como presidente interino: em junho de 2016, parte considerável de técnicos e chefias (vinte e três no total) foi exonerada, afetando a organização dessa Secretaria. Programas ligados à educação em direitos humanos e para a diversidade étnico-racial perderam a estrutura e a própria importância dentro do MEC.

O principal ataque da gestão Temer, porém, foi a aprovação da Emenda Constitucional $n^{0}$ 95 (BRASIL, 2016), decorrente da tramitação da PEC 55/2016, popularmente conhecida como "PEC do Fim do Mundo". Tal Emenda congelou os gastos públicos da União (Executivo, Legislativo e Judiciário) por um período de vinte anos - tais investimentos só podem crescer conforme a inflação do ano anterior. De acordo com estudo técnico da Consultoria de Orçamento da Câmara dos Deputados, para a área educacional, isso significaria perdas da ordem de mais de $\mathrm{R} \$ 25$ bilhões por ano. Tal medida retirou importantes recursos da educação pública, prejudicando as camadas mais desfavorecidas da população.

Jair Bolsonaro (2019-em andamento) foi eleito com um discurso crítico em relação às demarcações de áreas para indígenas e para quilombolas. Em 05 de abril de 2017, durante evento para a comunidade judaica na Hebraica do Rio de Janeiro, disse os seguintes despautérios: "Eu fui num quilombo [...] . O afrodescendente mais leve lá pesava sete arrobas. Não fazem nada. Eu acho que nem para procriador ele serve mais". "Se eu chegar lá (na Presidência), não vai ter dinheiro pra ONG. Esses vagabundos vão ter que trabalhar. [...] não vai ter um centímetro demarcado para reserva indígena ou para quilombola". Ou seja, trata esses seres humanos, detentores de garantias constitucionais - por exemplo, o direito à demarcação de seus territórios -, como animais. No governo, corriqueiramente declara sua aversão aos direitos dos povos indígenas, chegando a afirmar, de forma cínica e contraditória, que manter índios em reservas é tratá-los como animais em zoológicos 4 .

O que se observa para as áreas da educação, dos direitos humanos e da diversidade é uma sequência de desmontes de políticas alicerçadas em outras gestões, desatinos, ineficiências administrativas e ausência de ações ou políticas sólidas e/ou inclusivas. Dois dos principais ministérios responsáveis em desenvolver políticas para essas áreas tiveram nomeações que beiram a chacota: Damares Alves, à frente do Ministério da Mulher, da Família e dos Direitos Humanos; Ricardo Vélez Rodríguez e Abraham Weintraub, no caso do Ministério da Educação. Tais ministros(a) mostram-se incapazes de garantir uma gestão profissional e racional da coisa pública. $O$ enfrentamento aos problemas que atingem a educação nacional e a busca de soluções para sanar as graves violações de 
direitos humanos não são levados em consideração. Ao contrário, as falas e as medidas desenvolvidas (ou não) por esses(a) gestores(a) demonstram que ocupam seus cargos justamente para bloquear avanços sociais que ocorreram em administrações passadas, desmontar ações ou políticas inclusivas em andamento ou propor projetos voltados a manter ou até a aumentar injustiças sociais históricas.

A importância ou descaso pode ser exemplificado ou comparado nas primeiras ações realizadas por Lula da Silva e Jair Bolsonaro: o primeiro presidente, em menos de dez dias de governo, apoiou a tramitação e sancionou, em 9 de janeiro de 2003, a Lei no 10.639, que havia sido decretada pelo Congresso Nacional, medida reivindicada pelo movimento social negro desde, ao menos, o período constituinte; o atual presidente publicou um tuíte, em 2 de janeiro de 2019, informando a extinção da SECADI e o desmonte das ações direcionadas à diversidade e à inclusão: "Ministro da Educação desmonta secretaria de diversidade e cria pasta de alfabetização. Formar cidadãos preparados para o mercado de trabalho. 0 foco oposto de governos anteriores, que propositalmente investiam na formação de mentes escravas das ideias de dominação socialista 5" (Jair Bolsonaro). A mensagem deixou em saia-justa o seu ministro da Educação, Vélez Rodriguez, que acabara de tomar posse e estava, no momento do tuíte, dialogando com jornalistas e negando o tal desmonte da Secretaria.

A SECADI tinha um papel importante no desenvolvimento de políticas educacionais inclusivas e no combate às desigualdades (de gênero, raça, social) e discriminações (Igbtfobia, racismo, machismo). Durante as gestões de Lula da Silva e de Dilma Rousseff, era o órgão responsável em criar e implementar políticas públicas educacionais para: a população jovem e adulta analfabeta ou com baixa escolarização (abrigava, por exemplo, o Programa Brasil Alfabetizado); comunidades indígenas, quilombolas e do campo; adolescentes e jovens em cumprimento de medidas socioeducativas e as pessoas adultas encarceradas.

Com Jair Bolsonaro no poder, louvado se tornou o tripé adjetivado: 0 ultraliberalismo radical, o militarismo reacionário e a religiosidade fundamentalista. Troque os adjetivos dos seus substantivos e a ordem para o progresso de poucos e o regresso de muitos continua a mesma. A oração se encerra com a descabida repulsa às ciências, ao conhecimento, aos direitos humanos e às políticas públicas que alargam oportunidades a todos e todas. 0 apoio ao esdrúxulo Escola Sem Partido (ou Escola "do meu" Partido), a ênfase no ensino domiciliar (ou prisão infantil domiciliar? e/ou desresponsabilização do Estado pelo direito à educação?), o programa conservador religioso e as posturas racistas, misóginas e Igbtfóbicas de componentes do governo comprovam que a Idade das Trevas pode ser a novidade em território nacional. 0 retorno a um passado sombrio - 0 da Ditadura Empresarial-Militar de 1964-1985, com seus diversos crimes de Estado cometidos (prisões, torturas e assassinatos de opositores, por exemplo) - comemorado como a novidade da estação. 
As visões sobre a África no Brasil persistem carregadas de estereótipos e preconceitos. Essas percepções repercutem negativamente na identificação racial do povo brasileiro, em especial da população negra, maioria no país. A discriminação racial contra os(as) negros(as) é alicerçada no fato de que as práticas e/ou contribuições de seus ancestrais são abafadas, marginalizadas e/ou deturpadas (SERRANO; WALDMAN, 2007). Os legados dos africanos para a ciência e a cultura universais são, na maior parte dos casos, simplificados, desprezados, ridicularizados ou excluídos dos currículos escolares brasileiros. Como afirmam Barros e Barbosa (2018, p. 244), "A história e cultura africana e afro-brasileira mostram uma variedade de experiências sociais que apontam para a abertura ao mundo, à vida, para a inclusão e não a exclusão do outro, para a solidariedade na história".

As posturas e ações antissociais do governo atual são preocupantes e inadmissíveis. Destaca-se a necessidade de políticas públicas que possam reverter o quadro de desigualdade racial, e não o contrário. Muitos problemas persistem: a negligência do Estado quanto ao extermínio da população jovem e negra, realizado especialmente por suas próprias forças de repressão; 0 encerramento da Seppir; o combate mais incisivo às desigualdades étnico-raciais presentes na área educacional, no acesso à renda, em cargos de chefia nos postos de trabalho. 0 direito a uma educação antirracista deve continuar no radar do movimento negro e de todas(os) aquelas(es) que lutam pela igualdade racial:

[...] todos que investigam e/ou militam no campo das relações étnico-raciais e educação também concordam que (...) é preciso efetivar uma educação que se posicione publicamente contra o racismo. Por isso, os intelectuais negros e negras e o movimento negro afirmam que a educação tem que ser antirracista. Por quê? Porque estruturalmente o Brasil é um país racista e para combater e superar esse fenômeno é necessário que todas as instituições sociais, sobretudo aquelas que se dedicam à formação das cidadãs e dos cidadãos, adotem 0 antirracismo como eixo de suas práticas, projetos e políticas. Ele tem que ser um princípio ético de todas as ações educativas (GOMES, 2018, p. 14).

A inauguração e o desenvolvimento da Licenciatura em Estudos Africanos e AfroBrasileiros da UFMA se inscrevem nesse cenário de disputas por políticas educacionais ligadas à diversidade e ao combate ao racismo, configurando-se enquanto um exemplo inovador de ação afirmativa.

\section{A LICENCIATURA EM ESTUDOS AFRICANOS E AFRO-BRASILEIROS DA UFMA}

Implantada em 2015, durante a gestão de Nilma Lino Gomes na Seppir e de Dilma Rousseff na presidência da república, a Licenciatura Interdisciplinar em Estudos Africanos e AfroBrasileiros da Universidade Federal do Maranhão (UFMA) procura contribuir para a formação de profissionais da educação e da administração pública no que tange ao ensino das Histórias e Culturas 
Africanas e Afro-Brasileiras e ao desenvolvimento de políticas públicas para a população negra. Tratase de uma graduação noturna presencial que oferta 40 (quarenta) vagas para ingresso anual de estudantes. Passados quase quatro anos da implantação, em março de 2019 foi reconhecida pelo MEC e obteve a nota 4 (considerado "Muito Bom", segundo os critérios da avaliação), em uma escala de 1 a 5 .

Tal proposta é fundamentada na Lei no 10.639/2003. Outros documentos legais que a apoiam são: Diretrizes Curriculares Nacionais para a Educação das Relações Étnico-Raciais e para o Ensino de História e Cultura Afro-Brasileira e Africana (2004); Portaria Normativa $n^{0} 21$ do Ministério da Educação (MEC), de 28 de agosto de 2013 , que obriga a promoção da igualdade racial e enfrentamento ao racismo nos programas e ações do MEC.

Essa fundamentação em documentos legais buscada na proposição pedagógica da Licenciatura se relaciona com a busca do movimento negro em pressionar o campo legal e as políticas públicas. Como bem afirma Arroyo (2007, p. 114, destaques nossos), o comprometimento do Estado e das estruturas de poder são os objetivos das reivindicações:

A prioridade das intervenções [do movimento negro] parece caminhar nessa direção, por exemplo, a inclusão de políticas de ações afirmativas, cotas compulsórias na Reforma da Educação Superior, revela, pressiona e reeduca imaginários racistas e provoca maiores resistências do que ações de convencimento e de educação para o diálogo intercultural. As intervenções caminham para obrigar o Estado através de políticas de Estado. Por aí, o combate ao racismo na sociedade e no sistema escolar adquire dimensões políticas mais estruturais: comprometer o Estado, suas políticas e instituições e seus sistemas normativos. Comprometer as estruturas de poder.

A Licenciatura, cuja sede fica no campus de São Luís, oferece uma graduação interdisciplinar em Ciências Humanas. As áreas do conhecimento englobadas são: Educação, Filosofia, História, Geografia, Sociologia, Letras e Música. A estrutura curricular do curso possui disciplinas da área de História que são voltadas diretamente à temática do curso, como: "África I: Sociedades e Culturas"; "África II: Colonialismo e Independências"; e "A Diáspora Africana". São oferecidas disciplinas concernentes aos estudos africanos e afro-brasileiros, algumas inéditas nos cursos superiores no país, como "Filosofia Africana"; "Sociologia Africana"; "Geografia da África I: população, cidades e geoeconomia"; e "Literatura africana e afro-brasileira" (UNIVERSIDADE FEDERAL DO MARANHÃO, 2015).

A cosmovisão epistemológica e hegemônica eurocêntrica continua presente nas mentalidades (não só) ocidentais. Daí a necessidade de se realizar reflexões acerca das repercussões que essa cosmovisão unicamente valorizada e tida como válida traz aos currículos. $O$ estudo do pensamento (tradições e filosofias) na África, Ásia e América Latina é um instrumento valioso de uma história que resgata o contradiscurso nãohegemônico, dominado, silenciado ou mesmo excluído, o da alteridade da modernidade (DUSSEL, 2002). 
Um dos principais objetivos desta Licenciatura é afirmar a História da África e de suas diásporas. A população negra, suas histórias, suas culturas e seus modos de pensar, nessa concepção, não são consideradas como simples objetos de estudo, ainda comuns em alguns estudos nas áreas das Ciências Humanas/Sociais - mas não só nelas. Ao contrário, todos esses aspectos advindos dos(as) africanos(as) e das diásporas africanas são tidos como conhecimentos acumulados pela humanidade, como todo conhecimento humano, não importando a origem étnico-racial, territorial de origem, matriz religiosa, entre outros fatores. Arroyo (2007) ressalva que a introdução, por lei (10.639/2003), da História da África, da memória e cultura negras insere o debate no cerne do núcleo duro do currículo.

A libertação epistêmica em relação ao conhecimento hegemonicamente eurocêntrico alicerça a proposição dessa Licenciatura. A emancipação dos conhecimentos dos povos da chamada "periferia" (em sentido oposto ao que se convencionou situar o eurocentrismo como sinônimo de "centro epistemológico") e a busca por um currículo e por uma construção histórica, literária, sociológica, filosófica e de um pensamento educacional que valorizem visões não-eurocêntricas da modernidade são pontos centrais dessa proposta.

Como salienta Castiano (2013, p. 55), ao destacar a importância da tomada de consciência de uma posição epistêmica, "[...] assumir crítica e conscientemente o facto de que nenhum ser humano, seja ele do ocidente ou do oriente, sul ou norte, pode pretender assumir-se como sujeito possuidor de um saber absoluto $6[. .]$.$" .$

Ao criticar a chamada "arrogância epistemológica", enfatiza-se/exige-se que o "outro" epistêmico tenha o seu espaço na produção do conhecimento construído no mundo. Mesmo em África, o desenvolvimento da educação deve também beber em fontes inovadoras originais ou estrangeiras, desde que se constitua o objeto de uma análise crítica e de uma reflexão voltada às realidades próprias do continente (HABTE; WAGAW; AJAYI, 2011).

O campo dos estudos africanos, seja no plano internacional, seja no nacional, vem colaborando no desenvolvimento de pesquisas que transformam as análises historiográficas sobre a História da África. Para Hountondji (2008, p. 149), a pergunta central que permeia as análises nessa área não poderia ser outra: em que medida são africanos os chamados estudos africanos? 0 autor beninense defende que as próprias sociedades africanas devem apropriar-se do conhecimento sobre elas, pois seria importante "[...] o desenvolvimento em África de uma tradição autónoma, confiante em si própria, de investigação e conhecimento que responda a problemas e questões suscitados directa ou indirectamente por africanos [...]". E complementa: o tipo ainda preponderante de pesquisa é extravertido, ou seja, guiado para fora, destinado a ir ao encontro das necessidades teóricas e práticas das sociedades do Norte? 
Towa (2015) afirma que o debate acerca do reconhecimento ou da construção da filosofia africana - com destaque à filosofia negro-africana - tem que se opor ao racismo colonial e às armadilhas do neocolonialismo e à ofensiva do dogmatismo das mitologias semíticas. A recuperação de uma antiga herança negro-africana a ser rejuvenescida deve ter um peso maior do que o simples significado de um empréstimo da cultura europeia. O mesmo deve ocorrer no que tange ao desenvolvimento do pensamento historiográfico africano. A interrelação entre as disciplinas se faz presente no âmbito dos estudos africanos, como ressalta Hountondji (2008, p. 150):

[...] entre a história africana e a sociologia africana existe, claramente, uma complementaridade objectiva, visto que a situação presente de qualquer sociedade decorre, directa ou indirectamente, do respectivo passado. Por outro lado, um bom conhecimento do presente e da lógica dos acontecimentos na vida actual pode oferecer pontos de vista úteis para compreender o passado. Assim, a sincronia remete para a diacronia e vice-versa. A história e a sociologia são apenas um exemplo. Podem encontrar-se relações similares entre todas as disciplinas que constituem os estudos africanos.

Hernandes (2016, p. 37) ressalta a importância de se abrir caminhos ou possibilidades heurísticas com um caráter mais descolonizador e que contribuam para uma melhor aproximação à(s) realidade(s) africana(s). Uma das primeiras tarefas e provavelmente a mais necessária, "[...] seja 0 trabalho de desconstrução da universalidade da história europeia como modelo de análise e interpretação de outras temporalidades, nelas a africana incluída [...]". Para auxiliar na busca pela autonomia dos processos históricos no continente, cita que é imprescindível recolocar o papel da interdisciplinaridade e dos estudos comparativos na produção do conhecimento histórico em torno do continente africano. Esse raciocínio se coaduna com a organização curricular da Licenciatura da UFMA.

A Licenciatura configura-se como uma ação afirmativa que objetiva colaborar para uma política pública de formação inicial de professores(as) que insira as Histórias Africanas e AfroBrasileiras. Sua proposta é decorrência da tentativa de coletivos negros e de seus apoiadores de (re)escrever uma História que visibilize a memória, os conhecimentos e as contribuições da população negra brasileira, dos africanos(as), das diásporas africanas no mundo no decorrer dos tempos e na atualidade:

A comunidade negra, nas suas mais variadas formas de organização política, não reivindica a educação somente como um direito social e humano. Não luta apenas por uma educação universal que se coloca na luta contra as desigualdades. Antes, ela exige uma educação que seja pública, laica e que reconheça, respeite e dialogue com a diversidade de maneira afirmativa (GOMES, 2018, p. 14).

José A. dos Santos (2008) afirma que as perspectivas de estudos intituladas de póscoloniais, estudos culturais ou mesmo estudos da diáspora têm como objetivo a busca de inversão da lógica usual na produção do conhecimento, em geral, realizada do centro para a periferia. 
Não se pode reservar às histórias de África um papel secundário e pequeno em relação às de outras regiões/povos. A história da humanidade é muito complexa e fruto de diferentes contribuições, de várias culturas, que nos deixaram como herança conhecimentos científicos e tecnológicos. E isso "[...] é fundamental para se começar a desconstruir a imagem de que existem povos superiores e inferiores" (SILVÉRIO, 2013, p. 15).

A inclusão das Histórias e Culturas Africanas e Afro-Brasileiras se relaciona com a democracia, com a inclusão de todos os sujeitos coletivos na história e nos direitos humanos. Silva (2015, p. 163-164) destaca a importância dessa inclusão curricular no fortalecimento da autoestima das pessoas negras, sobretudo das crianças:

\begin{abstract}
Como explicar às crianças negras e também às não negras que os afrodescendentes são os únicos brasileiros, pelo menos a significativa maioria deles, que desconhecem precisamente de onde vieram seus antepassados? Seus antepassados aprisionados, escravizados e para cá forçadamente transportados guardaram em usos, costumes e até mesmo na língua portuguesa, lembranças contundentes das suas culturas e sabedoria africanas. Mas sofrimentos causados pela desumanização de seus corpos e mentes, a separação e 0 isolamento de nativos de um mesmo povo, deixaram pistas remotas sobre região, vila, cidade de que eram originários. Tiveram, eles, que se reinventar como seres humanos, como africanos da Diáspora. Se essa situação constrange adultos, imagine-se o quanto interfere no fortalecimento da autoestima das crianças negras, também das outras, as não negras. Como ensinar que somos todos iguais, diante de tão forte desigualdade? Que cidadania poderão essas crianças construir?
\end{abstract}

Descolonizar o currículo, democratizar o processo de formação na educação básica e no ensino superior e garantir a reflexividade e a autonomia colaboram na construção de espaços de intercâmbio e de diálogo que subsidiam reconhecer quando uma determinada metodologia ou certo conteúdo estariam marginalizando e/ou discriminando minorias sociológicas em nome de uma maioria ideológica e hegemônica, mesmo que não seja maioria demográfica. (HERNANDES. 2016, p. 40).

A intersecção das histórias e culturas africanas com a brasileira auxilia a valorizar positivamente as relações entre os diversos grupos étnico-raciais que convivem no Brasil, desde que realizada sem estereótipos ou romantizações. O desconhecimento dessa intersecção, em via contrária, produz visões distorcidas, que repercutem em discriminações raciais que vitimam negros(as). A Licenciatura examinada representa um importante suporte no processo de valorização da história dos povos africanos e do reconhecimento dos seus contributos na formação social brasileira.

\title{
4 CONSIDERAÇÕES FINAIS
}

Quando se analisa as políticas públicas voltadas à população negra e à inserção das Histórias e Culturas Africanas e Afro-Brasileiras nos currículos escolares, observa-se, de 2003 para cá, dois momentos distintos: 1) de 2003 a 2016, alcançou-se um avanço jamais visto na história brasileira, 
com a implantação de leis, criação de órgãos de apoio e de políticas públicas inclusivas, fruto de muita luta e reivindicação do movimento social negro que foram, de certo modo, apoiadas pelas gestões Lula da Silva e Dilma Rousseff, em que pesem os desacertos e a falta de maiores suportes financeiros; 2) de 2016 aos dias atuais, durante as gestões Temer e início de Bolsonaro, as políticas foram ou estão sendo menosprezadas, sucateadas e desmontadas.

O desenvolvimento da Licenciatura em Estudos Africanos e Afro-Brasileiros da UFMA, iniciativa inédita no país, trouxe uma contribuição importante, enquanto uma ação afirmativa que questiona as lógicas universalistas de igualdade e o currículo eurocêntrico presente na educação básica e no ensino superior. Afirma as Histórias e as cosmovisões dos povos africanos e afrodiaspóricos como conhecimentos legítimos e científicos. Isso tem uma relação direta com os direitos humanos e com a democracia, ao descolonizar o currículo. E direitos humanos e democratização do saber é o que o país mais precisa nesse momento.

\section{REFERÊNCIAS}

ARROYO, M. G. A pedagogia multirracial popular e o sistema escolar. In: GOMES, N. L. (org.). Um olhar além das fronteiras: educação e relações raciais. Belo Horizonte: Autêntica, 2007, p. 111-130.

BARROS, Antônio E. A.; BARBOSA, Viviane de O. Estudos Africanos e Afro-Brasileiros em perspectiva extensionista. Outros Tempos, São Luís, vol. 15, n. 26, 2018, p. 244.

BRASIL. Diretrizes curriculares nacionais para a educação das relações étnico-raciais e para o ensino de história e cultura afro-brasileira e africana. Brasília, DF: MEC/SEPPIR, 2004.

Emenda Constitucional № 95, de 15 de dezembro de 2016. Altera o Ato das Disposições Constitucionais Transitórias, para instituir o Novo Regime Fiscal, e dá outras providências.

Lei $\mathrm{n}^{0}$ 11.645, de 10 de março de 2008. Altera a Lei $n^{0}$ 9.394, de 20 de dezembro de 1996, modificada pela Lei $n^{0} 10.639$, de 9 de janeiro de 2003, que estabelece as Diretrizes e Bases da Educação Nacional, para incluir no currículo oficial da rede de ensino a obrigatoriedade da temática "História e Cultura Afro-Brasileira e Indígena". Brasília, DF, 2008.

Lei $n^{0} 10.639$, de 9 de janeiro de 2003. Altera a Lei $n^{0}$ 9.394, de 20 de dezembro de 1996, que estabelece as Diretrizes e Bases da Educação Nacional, para incluir no currículo oficial da Rede de Ensino a obrigatoriedade da temática "História e Cultura Afro-Brasileira", e dá outras providências. Brasilia, DF, 2003.

Lei $n^{0}$ 9.394, de 20 de dezembro de 1996. Estabelece as Diretrizes e Bases da Educação Nacional. Brasília, DF, 1996.

Lei $\mathrm{n}^{0} \mathbf{1 2 . 2 8 8}$, de 20 de julho de 2010. Institui o Estatuto da Igualdade Racial; altera as Leis nos 7.716, de 5 de janeiro de 1989, 9.029, de 13 de abril de 1995, 7.347, de 24 de julho de 1985, e 10.778, de 24 de novembro de 2003. Brasília, DF, 2010. 
Plano nacional de implementação das diretrizes curriculares nacionais para a educação das relações étnico-raciais e para o ensino de história e cultura afro-brasileira e africana. Brasília, DF: SECAD; SEPPIR, 2009. Disponível em: http://www.seppir.gov.br/.arquivos/leiafrica.pdf. Acesso em: 10 maio 2013.

; MEC. Portaria Normativa $n^{0} 21$, de 28 de agosto de 2013. Dispõe sobre a inclusão da educação para as relações étnico-raciais, do ensino de História e Cultura Afro-Brasileira e Africana, promoção da igualdade racial e enfrentamento ao racismo nos programas e ações do Ministério da Educação, e dá outras providências. Brasília, DF: MEC, 2013.

CARVALHO, Marcelo P. Licenciatura em Estudos Africanos e Afro-Brasileiros da UFMA: ações afirmativas para a democratização do saber. Kwanissa, São Luís, v. 1, n. 1, jan./jul. 2018, p. 5-23.

CASTIANO, José P. Os saberes locais na academia: condições e possibilidades de sua legitimação. Maputo: Educar; CEMEC; Universidade Pedagógica, 2013.

CASTIANO, José P.; NGOENHA, Severino E. Pensamento engajado: ensaios sobre filosofia africana, educação e cultura política. Maputo: Educar; CEMEC; Universidade Pedagógica, 2011.

DUSSEL, Enrique. Ética da libertação: na idade da globalização e da exclusão. Petrópolis: Vozes, 2002.

GOMES, Nilma L. Apresentação. In: SILVA, Paulo V. B. da; REGIS, Kátia; MIRANDA, Shirley A. de (orgs.). Educação das relações étnico-raciais: o estado da arte. Curitiba: NEAB-UFPR e ABPN, 2018, p. 13-18.

HABTE, A.; WAGAW, T.; AJAYI, J. F. A. Educação e mudança social. In: MAZRUI, A. A.; WONDJI, C. História geral da África: África desde 1935. 2.ed.São Paulo: Cortez; Brasília, DF: UNESCO, 2011.v. 8 , p. 817-841.

HERNANDES, H. G. Afinal, África é patrimônio de quem?: descolonizar o conhecimento como proposta curricular. In: PAULA, S. M. de; CORREA, S. M. de S. (org.). Nossa África: ensino e pesquisa. São Leopoldo: Oikos, 2016. p. 31-40.

HOUNTONDJI, Paulin J. Conhecimento de África, conhecimento de Africanos: Duas perspectivas sobre os Estudos Africanos. Revista Crítica de Ciências Sociais, 80, Março 2008.

SANTOS, Boaventura de S. Direitos humanos, democracia e desenvolvimento. In: SANTOS, B. de S.; CHAUI, M. Direitos humanos, democracia e desenvolvimento. São Paulo: Cortez, 2013, p. 41-133.

SANTOS, J. A. Diáspora africana: paraíso perdido ou terra prometida. In: MACEDO, J. R. Desvendando a história da África. Porto Alegre: Ed. UFRGS, 2008, p. 181-192.

SERRANO, Carlos; WALDMAN, Maurício. Memória D’África: a temática em sala de aula. São Paulo: Cortez, 2007.

SILVA, Petronilha B. G. e. Crianças negras entre a assimilação e a negritude. Revista Eletrônica de Educação, v. 9, n. 2, p. 161-187, 2015. 
SILVÉRIO, V. R. Apresentação. In: UNESCO; MEC; UFSCar. Síntese da coleção história geral da África: Pré-história ao século XVI / coordenação de Valter Roberto Silvério e autoria de Maria Corina Rocha, Mariana Blanco Rincón, Muryatan Santana Barbosa. Brasília, DF: 2013. p. 7-16.

TOWA, Marcien. A ideia de uma filosofia negro-africana. Belo Horizonte: Nandyala; Curitiba: NEABUFPR, 2015.

\section{UNIVERSIDADE FEDERAL DO MARANHÃO. Projeto Político-Pedagógico da Licenciatura Interdisciplinar em Estudos Africanos e Afro-brasileiros. São Luís, 2015.}

\section{Notas}

${ }^{1}$ A Lei $n^{0} 11.645$, de 10 de março de 2008, altera a LDB, anteriormente modificada pela Lei no 10.639 , para incluir no currículo oficial das redes de ensino a obrigatoriedade da temática "História e Cultura Afro-Brasileira e Indígena".

2 A Seppir, que tinha status de Ministério, teve a nomenclatura posteriormente modificada para Secretaria de Políticas de Promoção da Igualdade Racial. Foi anexada, em meados de 2015, ao novo Ministério da Igualdade Racial, das Mulheres e dos Direitos Humanos. Porém, após a presidente eleita Dilma Rousseff ter sido retirada do poder, esse Ministério foi extinto.

${ }^{3}$ A de maior repercussão foi quando pediu ao governo para acumular a aposentadoria e 0 salário de ministra (respectivamente, $R \$ 30.400,00$ e $R \$ 30.934,00$ ), pois, segundo ela, estava vivendo situação semelhante ao "trabalho escravo", uma vez que recebia "apenas" o teto do funcionalismo público ( $R \$ 33.700,00$ - aposentadoria mais salário). Após ser alvo de muitas críticas de movimentos sociais (indígenas, movimento negro etc.) e de outros setores da sociedade, Luislinda Valois acabou entregando o cargo em fevereiro de 2018.

4 Em 30 de novembro de 2018, durante visita à região do Vale do Paraíba (Guaratinguetá e Cachoeira Paulista), Jair Bolsonaro, ao ser questionado, por um jornalista, sobre a capacidade do futuro governo em reduzir o desmatamento, a emissão de gases de efeito estufa e cumprir as metas do Acordo de Paris, respondeu: "Sobre o acordo de Paris, nos últimos 20 anos, eu sempre notei uma pressão externa - e que foi acolhida no Brasil - no tocante, por exemplo, a cada vez mais demarcar terra para índio, demarcar terra para reservas ambientais, entre outros acordos que no meu entender foram nocivos para o Brasil. Ninguém quer maltratar o índio. Agora, veja, na Bolívia temos um índio que é presidente. Por que no Brasil temos que mantê-los reclusos em reservas, como se fossem animais em zoológicos?".

${ }^{5}$ Apesar da citação na rede social, o governo, até a data de fechamento deste artigo, não havia lançado qualquer programa voltado à formação de profissionais para o mercado de trabalho.

${ }^{6}$ Em outro texto, Castiano e Ngoenha (2011) defendem o conceito de "intersubjectivacção", que seria, no contexto da África atual, mais adequado do que o conceito de "interculturalidade". Para os autores, embora o termo "cultura" faça referência à dimensão antropológica e o diálogo intercultural ter a possibilidade de se realizar de maneira horizontal, são os sujeitos epistemológicos - e não as culturas - que têm a possibilidade de dialogar. Os inter-sujeitos africanos em ação é que seriam os responsáveis engajados em construir espaços de intersubjetivaç̧ão, em realizar a práxis filosófica. A educação seria o lócus privilegiado para a sua efetivação e a Liberdade seria o paradigma axiológico e a condição fundamental à emancipação da própria filosofia africana. Nesse sentido, a intersubjectivacção tratar-se-ia de um projeto de "desconstrução" e de "construção" epistêmicas da ideia de África.

7 Sobre essa questão, recomenda-se observar as críticas de Hountondji (2008, p. 152-156) à etnofilosofia e ao que ele denomina como "pecado original" que demarcam os estudos africanos na Europa durante o séc. XX. 